\title{
ANNOUNCEMENT OF GRADUATE COURSES IN TROPICAL SCIENCE IN 1971
}

In 1971 the Organization for Tropical Studies, a consortium of 27 Latin and U.S. universities created to promote an understanding of tropical environments and their intelligent use by man, will offer its ninth consecutive year of graduate studies in tropical science in Central America. A total of eight courses will be distributed through three semesters commencing on February 1, 1971. Graduate credit for eight semester hours may be earned through the University of Costa Rica. Courses will be offered in the following disciplines: Terrestrial Biology and Ecology, Forestry, Geography, Earth Sciences, and Atmospheric Sciences. Most of these will be offered in Costa Rica or Guatemala, although the Earth Science study will be concentrated in the islands of the West Indies.

All of the OTS courses are field oriented and highly intensive. The program is interdisciplinary in nature and problem oriented. Most of the students will undertake one or more limited research projects during the training period. The faculty is selected from universities throughout the Americas, and the students are chosen on the basis of academic excellence and tropical research interests.

Most or all of the student expenses are paid under a grant from the National Science Foundation to the OTS.

Courses and closing dates for applications are indicated as follows:

Winter Term

Tropical Biology, An Ecological Approach

November 15, 1970

Spring Term

Habitat Exploitation and Diversity: An Ecological

Approach with Vertebrates January 15, 1971

Forestry in the Developing Tropics: The Costa Rican Example January 15, 1971

Summer Term

Recent Carbonate Sedimentation and Early Diagenetic Processes, British West Indies March 7, 1971

Tropical Biology: An Ecological Approach-Section I April 1, 1971

Tropical Biology: An Ecological Approach-Section II April 1, 1971

Physical Landscape and Settlement Patterns in Selected Areas of Central America

Atmospheric Energy Considerations in a Tropical April 1, 1971 Environment April 1, 1971

A descriptive catalog of the courses and applications for enrollment may be obtained from:

The Organization for Tropical Studies

North American Office

5900 S. W. 73rd St.

South Miami, Florida 33143 